\title{
On the role of vertical ground heat flux for analytical simulation of borehole heat exchangers
}

Peter Bayer
J aime A. Rivera
Philipp Blum

\begin{abstract}
Analytical modelling techniques are frequently used for prediction of the impacts of borehole beat exchangers (BHEs) on the thermal conditions in the subsurface. They are appealing because they are easy to use, compact and computationally efficient. However, analytical formulations also cut down the complexity of the conditions in the field by limited resolution of variations in space and time, and by often simplified specifications of boundary conditions. In this presentation, we focus on the definition of the land surface boundary condition in line source solutions. As BHEs are thin elongated forms that can be approximated by a linear shape function, main attention is on the radial heat transfer, but less on the axial effects. Given the long operation time, however, the sharp physical boundary at the top may exert a substantial influence on the temperature evolution in the shallow ground and thus influence the performance of the ground source heat pump. We examine different formulations with Dirichlet and Cauchy type boundaries included in the line source equation, with and without horizontal groundwater flow. Both homogeneous as well as inhomogeneous implementations are presented, which offer new flexibilities for simulation of nonuniform land surface impacts such as associated with varying land use types. The presented approach also facilitates to account for the accelerated ground heat flux due to global warming and due to urbanization such as observed in so-called subsurface urban heat islands in many cities.
\end{abstract}

\section{NTRODUCTI ON}

Shallow geothermal energy use by borehole heat exchangers (BHEs) focus on the heat stored just below the ground surface. Usually, BHEs are drilled to a depth of 80 - $400 \mathrm{~m}$, but for example in Germany, most installations do not reach much deeper than $100 \mathrm{~m}$ (Stauffer et al. 2013). Energy balance calculations for such systems show that long term heat extractions source mainly energy stored in the ground (Nouanegue et al. 2009). However, cooling of the ground accelerates heat flux through the ground surface. Considering a full life cycle of a BHE, which covers the period of operation and recovery afterwards, around two thirds of the energy deficit in the ambient ground is filled up by heat transfer from the ground surface (Rivera et al. 2015b). This emphasizes the importance of considering or neglecting heat flux from the ground surface in BHE simulation and design.

The shallow geothermal energy reservoir benefits from global warming. Due to atmospheric temperature increase, ground heat will naturally increase in the future. Beltrami et al. (2002), has estimated that for the last half of the 20th century, the mean continental ground heat flux in the subsurface has been around $39 \mathrm{~mW} / \mathrm{m}^{2}$. The distribution of the associated ground heat gain is heterogeneous in space and time (Kurylyk et al. 2014; Benz et al.

Peter Bayer (mail@bayerpeter.com) is a professor of geothermics at Ingolstadt University of Applied Sciences, Jaime A Rivera holds a Ph.D. degree in Earth Sciences, and Philipp Blum is a professor of Engineering Geology at the Karlsruhe Institute of Technology (KIT), Germany. 
2017). In urban environments, temperatures in shallow ground have been rising even more since industrialization. This is not simply a consequence of urban heat islands in the atmosphere that are thermally coupled with the ground (Kataoka et al. 2009) (Fig. 1a). Recently, attention to the so-called subsurface urban heat islands (Ferguson and Woodbury 2007) has been growing, especially because in cold and moderate climates such as those found in central Europe, large scale thermal anomalies are found beneath cities (Menberg et al. 2013; Benz et al. 2015; Bayer et al. 2016; Mueller et al. 2018). Compared with their counterpart in the atmosphere, much more pronounced permanent thermal anomalies are measured, and thus subsurface urban heat islands have a substantial geothermal potential (Zhu et al. 2010; Radioti et al. 2017; Rivera et al. 2017). As an example, Fig. 1b depicts two typical temperature profiles recorded in BHEs before start of operation, using a wireless temperature logger, in urbanized areas of Switzerland NIMO-T (Rohner et al. 2005). The profiles are site-specific, but all delineate clearly increased temperatures in the uppermost tens of meters. BHE simulation techniques that account for such vertical temperature variations, however, are not common (Bandos et al. 2009).

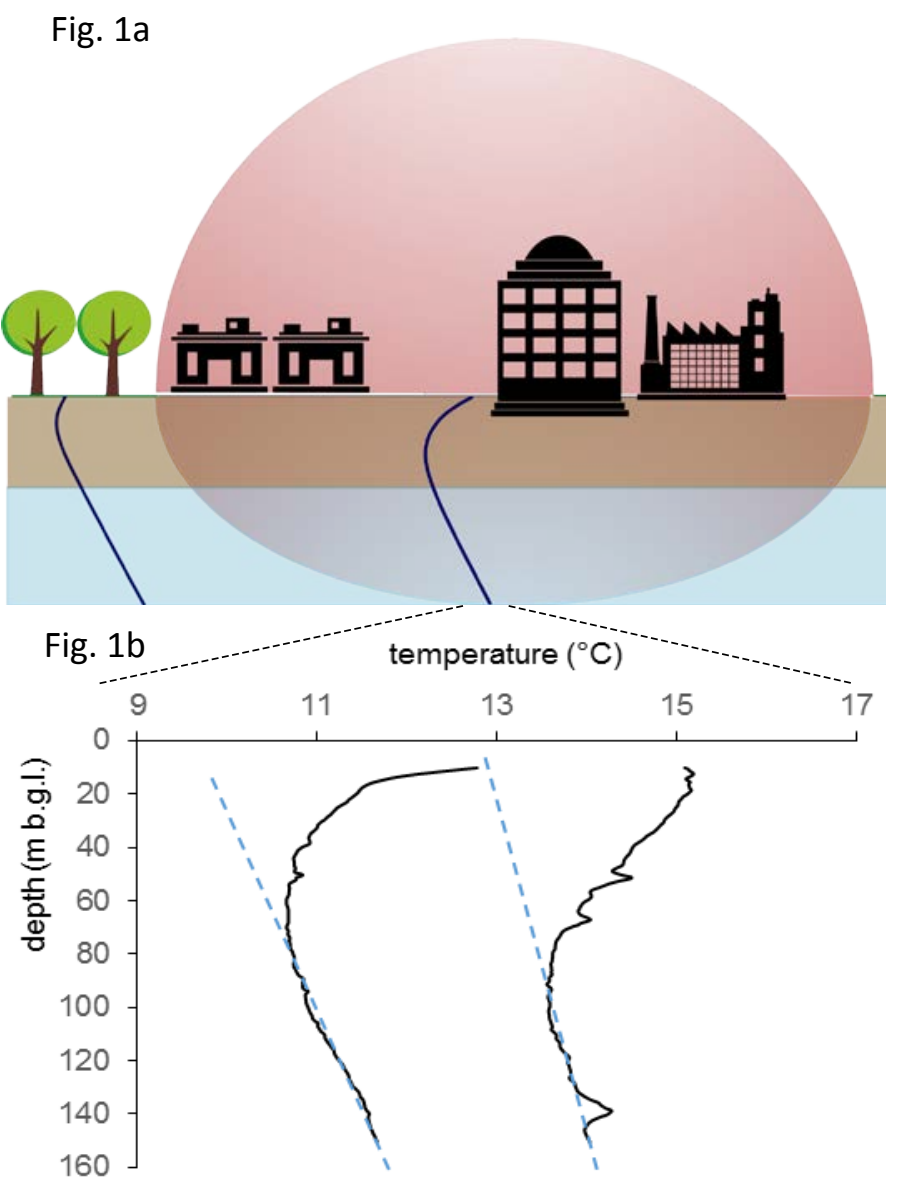

Figure 1 a) Illustration of atmospheric and subsurface urban heat islands with characteristic borehole temperature profiles through the shallow ground and groundwater. The bottom plot (b) depicts two measured profiles in Switzerland (black curves), with comparison of the interpolated temperature trend based on the (expected) ambient geothermal gradient (blue dashed lines). 
In a series of recent papers, we presented and applied analytical modelling concepts that account for ambient ground warming in different ways and include ground heat flux processes based on the common line-source equation approach (Rivera et al. 2015a; Bayer et al. 2016; Rivera et al. 2016b, 2016a). We distinguished implementations with fixed temperature and Cauchy (or Robin) type top boundary conditions (BCs) to capture the heat transfer processes at the ground surface. This was complemented by moving line source formulations, including the effect of horizontal groundwater flow. It was revealed that, when taking the city of Zurich as a study case, each degree of ground heating saves $4 \mathrm{~m}$ of the borehole to supply a given heat demand. In highly urbanized regions, heat extraction can be increase by $13 \%$ to $40 \%$ depending on BHE layout, depths and physical ground conditions. These values clearly demonstrate the importance of accounting for elevated ground temperatures and heat flux in urban environments for proper BHE planning. In contrast, by ignoring such effects, the renewability of shallow geothermal systems will be undervalued and the performance of BHEs for heat extraction will be underestimated. When the focus is set on cooling by means of BHEs or geothermal wells, however, ambient ground heating in the future represents a clear disadvantage, e.g. (Epting et al. 2013).

In this presentation, we present a line source formulation, which includes a non-homogeneous $\mathrm{BC}$ to account for spatially variable heat exchange at the land surface. It is applied to example cases with different heat flux into the subsurface as a consequence of variable land use in the surrounding of a BHE. We inspect the role of different BC formulations on the thermal regime in the ground, including conditions with horizontal groundwater flow. The findings are useful for revealing the consequence of elevated ground heat flux in an urban environment on the longterm performance of BHEs.

\section{METHODOLOGY}

The coupled thermal interaction between BHEs and non-uniform transient ground surface effects is accounted for via superpositioning of Green's functions (Rivera et al. 2016b, 2016a). Considering the model shown in Figure 2 and for the general case where the thermal regimes above and below the ground surface are coupled through Cauchy type $\mathrm{BCs}$, the solution reads:

$$
T_{C}=\omega_{C}+\beta_{C}
$$

where $T_{\mathrm{C}}$ is temperature at any point in time within the half-space, and $\omega_{\mathrm{C}}$ and $\beta_{\mathrm{C}}$ are respectively solutions of the associated non-homogenous and homogeneous boundary value problems:

$$
\begin{aligned}
& \beta_{C}=\beta_{M F L S}\left(\boldsymbol{x}, \boldsymbol{x}^{\prime}, t\right)+\Delta \beta_{C}\left(\boldsymbol{x}, \boldsymbol{x}^{\prime}, t\right) \\
& \begin{aligned}
\beta_{M F L S}\left(\boldsymbol{x}, \boldsymbol{x}^{\prime}, t\right) & =\frac{q}{8 \lambda \pi} \exp \left(\frac{x-x^{\prime}}{2 a} v\right) \int_{r_{d}^{2}}^{\infty} \frac{1}{\varphi} \exp \left[-\varphi-\left(\frac{r_{d} v}{4 a}\right)^{2} \frac{1}{\varphi}\right]\left\{2 \operatorname{erf}\left(\frac{z}{r_{d}} \sqrt{\varphi}\right)\right. \\
& \left.-\operatorname{erf}\left(\frac{z-H}{r_{d}} \sqrt{\varphi}\right)-\operatorname{erf}\left(\frac{z+H}{r_{d}} \sqrt{\varphi}\right)\right\} d \varphi
\end{aligned}
\end{aligned}
$$




$$
\begin{aligned}
& \Delta \beta_{C}\left(x, x^{\prime}, t\right)=\frac{q}{4 \lambda \pi} \exp \left(\frac{x-x^{\prime}}{2 a} v\right) \int_{\frac{r_{d}^{2}}{4 a t}}^{\infty} \frac{1}{\varphi} \exp (-\varphi \\
& \left.-\left(\frac{r_{d} v}{4 a}\right)^{2} \frac{1}{\varphi}\right)\left\{\operatorname { e x p } ( h z + ( \frac { h r _ { d } } { 2 } ) ^ { 2 } \frac { 1 } { \varphi } ) \left[\operatorname{erfc}\left(\frac{z \sqrt{\varphi}}{r_{d}}+\frac{h r_{d}}{2 \sqrt{\varphi}}\right)\right.\right. \\
& \left.\left.-\exp (h H) \operatorname{erfc}\left(\frac{z+H}{r_{d}} \sqrt{\varphi}+\frac{h r_{d}}{2 \sqrt{\varphi}}\right)\right]\right\} d \varphi \\
& \omega_{C}(x, t)=\frac{H h}{16} \int_{\frac{H^{2}}{4 a t}}^{\infty} T_{s}\left(t-\frac{H^{2}}{4 a \varphi}\right)\left\{\frac{2}{\sqrt{\pi \varphi^{3}}} \exp \left[-\left(\frac{z}{H}\right)^{2} \varphi\right]\right. \\
& \left.-\frac{H h}{\varphi^{2}} \operatorname{erfc}[\sigma(z, \varphi)] \exp [\rho(z, \varphi)]\right\} \Delta(x, \varphi) d \varphi, \quad z \neq 0
\end{aligned}
$$

with:

$$
\begin{gathered}
\Delta(\boldsymbol{x}, \varphi)=\left[\operatorname{erf}\left(\frac{y-y_{b}}{H} \sqrt{\varphi}\right)-\operatorname{erf}\left(\frac{y-y_{a}}{H} \sqrt{\varphi}\right)\right]\left[\operatorname{erf}\left(\frac{x-x_{b}}{H} \sqrt{\varphi}-\frac{v H}{4 a \sqrt{\varphi}}\right)\right. \\
\left.-\operatorname{erf}\left(\frac{x-x_{a}}{H} \sqrt{\varphi}-\frac{v H}{4 a \sqrt{\varphi}}\right)\right]
\end{gathered}
$$

$\rho(z, \varphi)=z h+\frac{(H h)^{2}}{4 \varphi}$

$r_{d}^{2}=\left(x-x^{\prime}\right)^{2}+\left(y-y^{\prime}\right)^{2}$

The related solution with prescribed temperature at the ground surface (Dirichlet BCs) can be obtained by considering the coupling coefficient $b$ infinite. A more detailed description of this coefficient can be found in Rivera et al. (2016a, 2016b). 


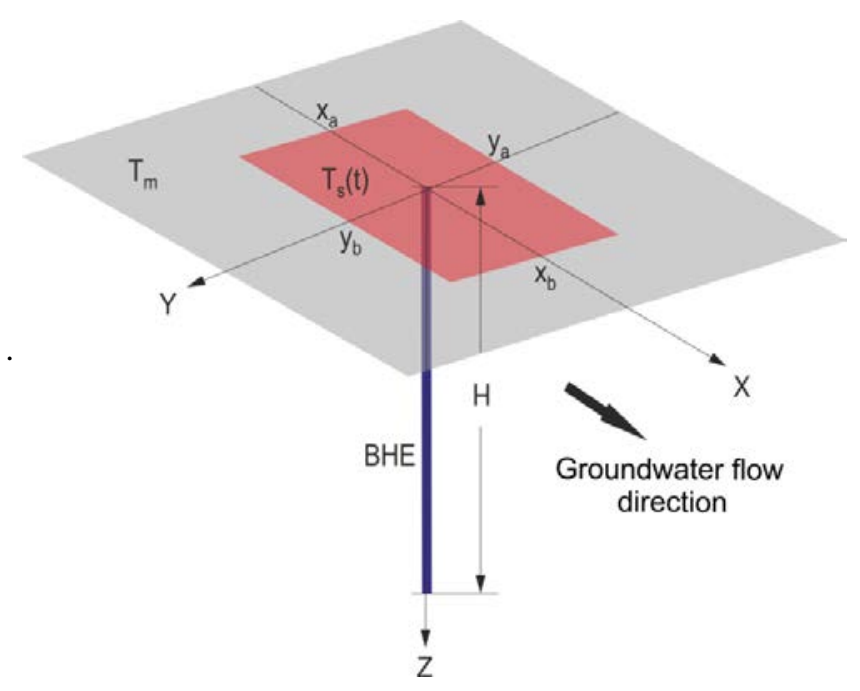

Figure 2 Conceptual model representing spatial variability of above-ground temperatures in urban environments. The red plane within the coordinates $\left[x_{a}, x_{b}\right]$ and $\left[y_{a}, y_{b}\right]$ represents a distinctive above-ground temperature, $T_{s}$, in comparison to the background conditions, given by the mean reference temperature $T_{m}$. BHE denotes the position of the vertical borehole heat exchanger (Rivera et al. 2016b).

\section{MODEL APPLI CATI ON AND RESULTS}

By superpositioning the model described in Figure 2, it is possible to estimate transient three-dimensional (3D) temperature fields such as the one illustrated in Figure 3. In this arbitrary scenario, heat is extracted from the ground via a BHE (located at $z$-arrow), while the basal heat losses from two buildings partially replenish the induced heat deficit. The buildings and the bare soil area are represented as planar sources with periodic above-ground temperatures with mean values of $22{ }^{\circ} \mathrm{C}$ and $12{ }^{\circ} \mathrm{C}$ respectively. The undisturbed ground temperature is $11^{\circ} \mathrm{C}$. Further model parameter settings are oriented at those utilized in (Rivera et al. 2016b). The figure demonstrates a strong influence of permanent local heat sources such as the buildings adjacent to a BHE. It also reveals the resulting nonuniform thermal regime in the ground assuming long term heat extraction by the BHE $(30 \mathrm{~W} / \mathrm{m})$ and ambient groundwater flow with Darcy flux of $10^{-7} \mathrm{~m} / \mathrm{s}$ in x-direction.

In the next step, we examine in more detail the role of thermal coupling at the land surface and choose the simple case delineated in Figure 2. The temperature (in dimensionless form) is calculated along the x-axis for different levels of coupling between the thermal fields below and above the ground surface. The coordinates $x_{a}$ and $x_{\mathrm{b}}$ are also normalized (here $x_{\mathrm{a}}=-0.5$ and $x_{\mathrm{b}}=0.5$ ) and indicate for instance, the boundaries of a building. Figure 4 describes the coupled thermal effect of a BHE extracting heat and spatially variable ground heat flux on the thermal regime at the ground surface. The BHE is located at $x=0$ as it is evident from the induced temperature minimum. The temperature directly above the building slab is 1 (dimensionless). This case is also delineated by the red dashed line corresponding to the solution assuming Dirichlet BCs $\left(\mathrm{T}_{\mathrm{D}}\right)$. This implies that the ground surface temperature is identical to the temperature directly above it. 


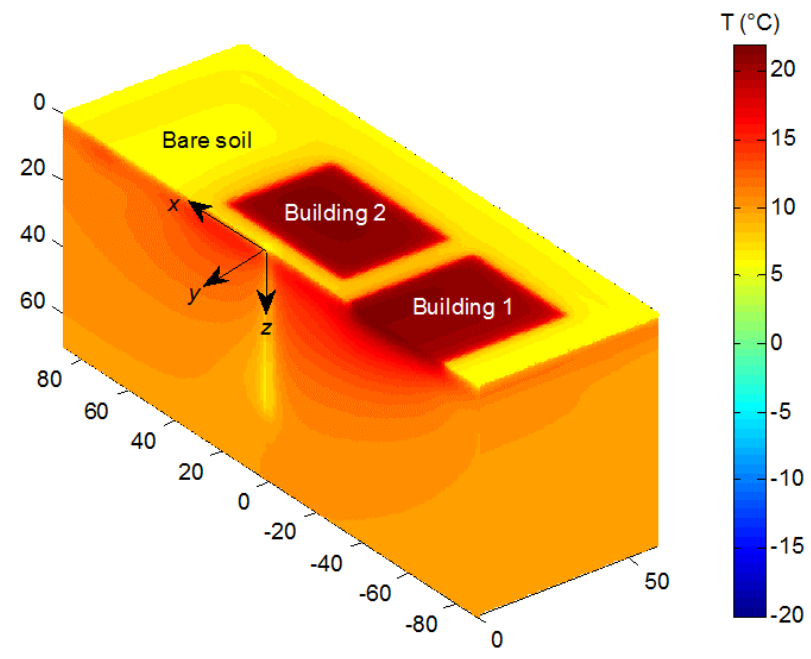

Figure 3 Temperature distribution after 25 years obtained with the analytical model for a synthetic exemplary scenario with two buildings and one BHE. Groundwater flows along the positive $x$ direction.

As the level of coupling (represented by the product $\mathrm{H} \cdot \mathrm{h}$ ) decreases, the difference between ground -and above ground surface temperature becomes more evident. This is a crucial point for simulating temperature fields near the ground surface (e.g. during the operation of very shallow geothermal systems) where most commonly prescribed BCs with fixed temperatures are assumed. Such settings have a crucial impact on the computed long term energy balance for geothermal systems since they govern the time-dependent power contribution from the shallow reservoir (Rivera et al. 2015b). The deeper BHEs are installed, the lower is the relative impact of the specification of the top boundary in the model. However, the impact of locally elevated ground heat flux grows with time. Considering BHE life times of decades, so even BHEs operating at a depth of $100 \mathrm{~m}$ can be remarkably influenced (Bayer et al. 2016; Rivera et al. 2017).

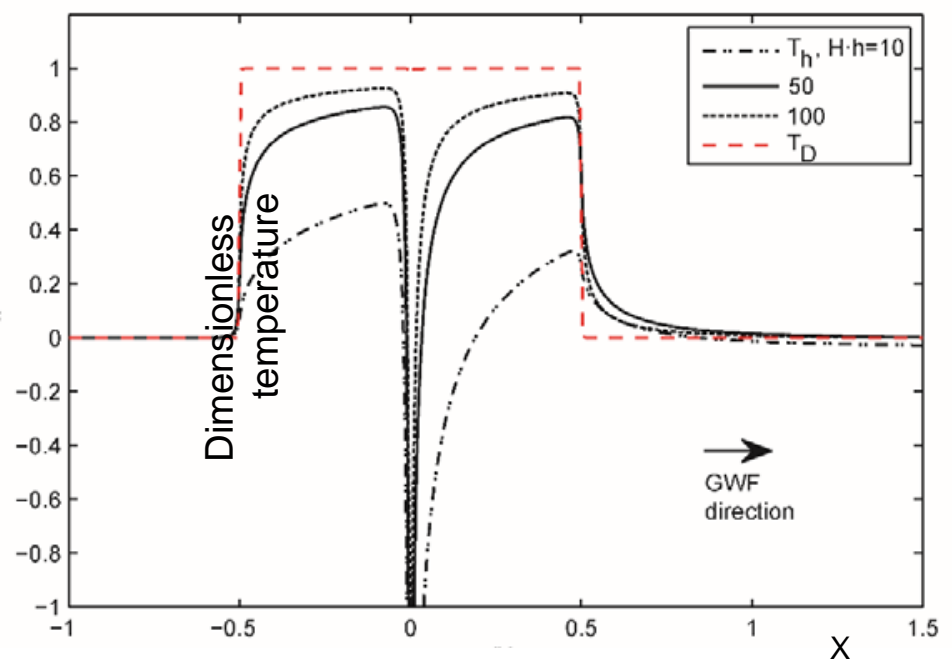

Figure 4 Dimensionless steady state ground surface temperature for the model shown in Figure 2. Dirichlet- $\left(\mathrm{T}_{\mathrm{D}}\right)$ and Cauchy-type $\left(\mathrm{T}_{\mathrm{h}}\right)$ BCs are compared changing the product $H \cdot h$ via the coupling coefficient $h$.. 


\section{CONCLUSIONS}

The presented discussion of nonuniform, spatially and temporally variable ground heat flux is crucial for facilitating a process-based prediction of the thermal regime evolving during decades of BHE operation. As demonstrated, complex heat transport mechansims at the land surface can be considered in standard line-source formulations by variable formulation of the top boundary condition in a superpositioned BHE model. The presented third type boundary condition (BC) offers more flexibility to the mathematical formulation of heat fluxes at the ground surface. Still, it is clear that any type of BC used in a mathematical model (e.g., the first-, second-, and thirdkind BCs) represents a simplified approximation to actual conditions. Therefore, the appropriate choice of BC needs to be decided for each case study individually.

As demonstrated, it is also possible to account for horizontal groundwater flow and advection, as well as multiple BHE fields. The obtained model framework can be used to simulate the transient 3D thermal regime in the ground and, for instance, elaborate in more detail parameter sensitivities. It is suitable for depicting the specific conditions beneath cities, and in particular the role of accelerated heat flux in the ground as observed in urban settlements worldwide. This is important, because in cities with evolving subsurface heat islands the (seasonal) regeneration potential of BHEs is improved. Considering a continuous increase in the density of geothermal installations in cities, proper characterisation of vertical heat flow mechanisms will thus gain interest in the future.

\section{ACKNOWLEDGEMENTS}

This work has been supported by the German Research Foundation (project BA2850/3-1).

\section{NOMENCLATURE}

$\begin{array}{ll}a & =\text { thermal diffusivity }\left(\mathrm{m}^{2} \mathrm{~s}^{-1}\right) \\ b & =\text { coupling coefficient }\left(\mathrm{m}^{-1}\right) \\ H & =\text { borehole length }(\mathrm{m}) \\ q & =\text { heat flow rate per unit length }\left(\mathrm{W} \mathrm{m}^{-1}\right) \\ r_{d} & =\text { horizontal radial distance from the borehole }(\mathrm{m}) \\ t & =\text { time }(\mathrm{s}) \\ T & =\text { temperature in the porous medium }\left({ }^{\circ} \mathrm{C}\right) \\ T_{m} & =\text { reference initial and surrounding temperature }\left({ }^{\circ} \mathrm{C}\right) \\ T_{s} & =\text { above-ground temperature }\left({ }^{\circ} \mathrm{C}\right) \\ X^{\prime} & =\text { coordinates vector where temperature is evaluated }(\mathrm{m}) \\ x^{\prime} & =\text { coordinates vector where a heat source is released }(\mathrm{m}) \\ x_{,}, y, z & =\text { single space coordinates where temperature is evaluated }(\mathrm{m}) \\ x_{a}, x_{b,} & =\text { boundary coordinates of the specific land use }(\mathrm{m}) \\ y_{a}, y_{b} & \\ x^{\prime}, y^{\prime}, & =\text { single space coordinates where heat sources are released }(\mathrm{m}) \\ z^{\prime} & \end{array}$

\section{Subscripts}


$C \quad=$ referring to Cauchy-type boundary conditions

$D \quad=$ referring to Dirichlet-type boundary conditions $\omega$
Abbreviations
$\mathrm{BC}=$ boundary condition
BHE = borehole heat exchanger
MFLS = moving finite line source

\section{REFERENCES}

Bandos, T. V., Á. Montero, E. Fernández, J. L. G. Santander, J. M. Isidro, J. Pérez, P. J. F. de Córdoba and J. F. Urchueguía. 2009. Finite line-source model for borehole heat exchangers: effect of vertical temperature variations. Geothermics 38 (2):263-270.

Bayer, P., J. A. Rivera, D. Schweizer, U. Schärli, P. Blum and L. Rybach. 2016. Extracting past atmospheric warming and urban heating effects from borehole temperature profiles. Geothermics 64:289-299.

Beltrami, H., J. E. Smerdon, H. N. Pollack and S. Huang. 2002. Continental heat gain in the global climate system. Geophysical Research Letters 29 (8):8-1-8-3.

Benz, S. A., P. Bayer and P. Blum. 2017. Global patterns of shallow groundwater temperatures. Environmental Research Letters 12 (3):034005.

Benz, S. A., P. Bayer, K. Menberg, S. Jung and P. Blum. 2015. Spatial resolution of anthropogenic heat fluxes into urban aquifers. Science of The Total Environment 524:427-439.

Epting, J., F. Händel and P. Huggenberger. 2013. Thermal management of an unconsolidated shallow urban groundwater body. Hydrology and earth system sciences 17:1851-1869.

Ferguson, G. and A. D. Woodbury. 2007. Urban heat island in the subsurface. Geophysical research letters 34 (23).

Kataoka, K., F. Matsumoto, T. Ichinose and M. Taniguchi. 2009. Urban warming trends in several large Asian cities over the last 100 years. Science of the total environment 407 (9):3112-3119.

Kurylyk, B. L., K. T. MacQuarrie and J. M. McKenzie. 2014. Climate change impacts on groundwater and soil temperatures in cold and temperate regions: Implications, mathematical theory, and emerging simulation tools. Earth-Science Reviews 138:313-334.

Menberg, K., P. Blum, A. Schaffitel and P. Bayer. 2013. Long-term evolution of anthropogenic heat fluxes into a subsurface urban heat island. Environmental science \& technology 47 (17):9747-9755.

Mueller, M. H., P. Huggenberger and J. Epting. 2018. Combining monitoring and modelling tools as a basis for city-scale concepts for a sustainable thermal management of urban groundwater resources. Science of The Total Environment 627:1121-1136.

Nouanegue, H.-F., A. S. Shirazi and M. Bernier. 2009. Extracted heat from geothermal boreholes: where does the energy come from. 4th Canadian Solar Buildings Conference, Toronto, Ontario.227-236.

Radioti, G., K. Sartor, R. Charlier, P. Dewallef and F. Nguyen. 2017. Effect of undisturbed ground temperature on the design of closed-loop geothermal systems: A case study in a semi-urban environment. Applied energy 200:89-105.

Rivera, J. A., P. Blum and P. Bayer. 2015a. Analytical simulation of groundwater flow and land surface effects on thermal plumes of borehole heat exchangers. Applied Energy 146:421-433.

Rivera, J. A., P. Blum and P. Bayer. 2015b. Ground energy balance for borehole heat exchangers: vertical fluxes, groundwater and storage. Renewable Energy 83:1341-1351.

Rivera, J. A., P. Blum and P. Bayer. 2016a. A finite line source model with Cauchy-type top boundary conditions for simulating near surface effects on borehole heat exchangers. Energy 98:50-63.

Rivera, J. A., P. Blum and P. Bayer. 2016b. Influence of spatially variable ground heat flux on closed-loop geothermal systems: Line source model with nonhomogeneous Cauchy-type top boundary conditions. Applied Energy 180:572-585.

Rivera, J. A., P. Blum and P. Bayer. 2017. Increased ground temperatures in urban areas: Estimation of the technical geothermal potential. Renewable energy 103:388-400.

Rohner, E., L. Rybach and U. Schärli. 2005. A new, small, wireless instrument to determine ground thermal conductivity in-situ for borehole beat exchanger design. Proceedings World Geothermal Congress.

Stauffer, F., P. Bayer, P. Blum, N. M. Giraldo and W. Kinzelbach. 2013. Thermal use of shallow groundwater: CRC Press. 
Zhu, K., P. Blum, G. Ferguson, K.-D. Balke and P. Bayer. 2010. The geothermal potential of urban heat islands. Environmental Research Letters 5 (4):044002. 